\title{
KOMODIFIKASI DALAM AJANG PENCARIAN BAKAT PENYANYI DANGDUT LIGA DANGDUT INDONESIA DI INDOSIAR
}

\author{
Kurniawan $^{1 *}$ dan Hayati Nupus ${ }^{2}$ \\ 1,2Universitas Paramadina, Jakarta, Indonesia \\ *blogiwank@gmail.com
}

\begin{abstract}
Liga Dangdut Indonesia (Indonesian Dangdut League) is a popular dangdut singer talent contest in Indosiar television station. It is part of the media strategy to gain ratings and audience share to compete for a slice of the limited advertising cake in the free-to-air commercial television broadcasting. This competiton encourages television managers to think hard to create flagship programs that become media commodities to attract viewers and advertisers. This study aims to identify some forms of commodification on Liga Dangdut Indonesia. Study of dangdut is important for communication research because it will help more understanding about the modern nation-state culture of Indonesia. Drawing on a critical political economy framework, this study uses Mosco's theory regarding processes of commodification of media content, audiences, and workers. Researchers added Fuchs's theory of digital workers to see the phenomenon of commodification in the digital age. This is a qualitative research with case study method. Data collection techniques are carried out by observation and interviews as well as exploring news, audiovisual material, and reports. Researchers found that commodification occurs in the contest in the form of the commodification of media content, audiences, workers, and digital workers. This commodification hides exploitative social relations by presenting them in a form that mistifies dangdut as global, upper-class, nobel culture.
\end{abstract}

Keywords: commodification, dangdut, Indosiar, entertainment

\begin{abstract}
Abstrak
Kontes pencarian bakat penyanyi dangdut Liga Dangdut Indonesia di stasiun televisi Indosiar merupakan bagian dari strategi media tersebut untuk meraih rating dan audience share dalam perebutan kue iklan di bisnis penyiaran. Perebutan ini mendorong para pengelola televisi berpikir keras untuk membuat programprogram andalan yang memikat penonton dan menarik pemasang iklan yang pada akhirnya menjadi komoditas andalan televisi tersebut. Penelitian ini bertujuan untuk mengidentifikasi bentuk-bentuk komodifikasi yang terjadi pada Liga Dangdut Indonesia di Indosiar. Penelitian mengenai budaya dangdut ini penting karena dapat membantu untuk lebih memahami budaya negara-bangsa modern Indonesia. Penelitian dilakukan dengan menggunakan pendekatan ekonomi politik komunikasi dari Vincent Mosco mengenai tiga jenis komodifikasi yang mungkin terjadi dalam industri komunikasi, yakni komodifikasi pada isi, khalayak (audience), dan pekerja media. Peneliti juga menambahkan teori Christian Fuchs mengenai pekerja digital untuk melihat fenomena komodifikasi di era digital. Penelitian ini merupakan penelitian kualitatif dengan metode studi kasus. Teknik pengumpulan data dilakukan dengan observasi dan wawancara serta menggali bahan audiovisual dan laporan. Peneliti menemukan bahwa komodifikasi terjadi dalam acara Liga Dangdut Indonesia dalam bentuk komodifikasi isi media, khalayak, pekerja, dan pekerja digital. Proses komodifikasi ini menyembunyikan hubungan-hubungan sosial eksploitatif dengan mempresentasikannya sebagai sebuah realitas yang memistifikasi dangdut sebagai budaya luhur, kelas atas, dan mengglobal.
\end{abstract}

Kata Kunci: komodifikasi, dangdut, Indosiar, hiburan

\section{PENDAHULUAN}

Komodifikasi budaya telah menjadi hal yang lumrah dalam kehidupan masa kini karena ia bergandengan tangan dengan konsumerisme. Setiap aspek budaya kini diubah ke dalam komoditas (Pröschel, 2012). 
Riset-riset akademis telah mengungkapkan bahwa kekuatan-kekuatan pasar telah mengubah praktik-praktik budaya ke dalam komoditas yang dapat dijual demi keuntungan ekonomis, penciptaan ruang, dan pembangunan identitas (Su, 2011).

Komodifikasi dalam industri televisi adalah bagian dari strategi dalam mengakumulasi kapital dan perluasan bisnis. Strategi lain adalah spasialiasi dengan perluasan dan konsentrasi kepemilikan media di tangan sejumlah kecil perusahaan (Sudibyo \& Patria, 2013).

Televisi di Indonesia masih menjadi media massa yang menangguk porsi iklan terbesar dibanding jenis media lain. Data Dentsu Aegis Network menunjukkan bahwa belanja iklan terbesar di Indonesia pada 2018 dikuasai oleh televisi $(54,1$ persen) dan suratkabar $(20,9$ persen) (Dentsu Aegis Network, 2019).

Adapun Adstensity mencatat bahwa total belanja iklan televisi pada 2018 menembus Rp 110,46 triliun, tumbuh $13,35 \%$ dibandingkan dengan periode 2017 (Widowati, 2019)..

Di sisi lain, biaya operasional televisi itu mahal dan iklan masih menjadi pemasukan utama mereka. Pada 2003, misalnya, biaya satu jam siaran saja sekitar Rp 50 juta, belum termasuk harga program yang rata-rata $\mathrm{Rp} 25-$ 350 juta. Padahal, rata-rata siaran televisi 2024 jam per hari. Kalau setiap jam butuh Rp 100 juta saja, maka biaya siaran dalam sehari minimal Rp 2 miliar (SWA Online, 2003).

Ongkos besar itu akan dapat tertutupi bila banyak iklan masuk. Tarif iklan Trans $T V$ di prime time, misalnya, dibanderol $\mathrm{Rp} 50$ juta per 30 detik (Sitanggang, 2015). Dengan perhitungan seperti itu, pengelola televisi harus kreatif dalam menciptakan program yang menangguk iklan banyak agar mendapat laba besar.

Namun, kue iklan yang menggiurkan itu harus diperebutkan oleh 13 stasiun televisi. Perebutan ini mendorong para pengelola televisi berpikir keras untuk membuat programprogram andalan yang memikat penonton dan menarik pemasang iklan. Acara-acara inilah yang kemudian menjadi komoditas andalan televisi.

Proses komodifikasi dalam acara televisi dapat dilihat dengan pendekatan ekonomi politik komunikasi. Pendekatan ini berpangkal dari konsep komoditas. Menurut Adam Smith, komoditas adalah bentuk tertentu dari produk ketika produksinya dikelola melalui proses pertukaran, yakni menjadi barang dagang. Komoditas terjadi dari berbagai kebutuhan yang muncul, termasuk memuaskan rasa lapar dan status kelompok sosial tertentu (Smith, 1977).

Dalam pendekatan ekonomi politik, komodifikasi dimaknai sebagai proses perubahan nilai guna menjadi nilai tukar atau, dengan kata lain, segala upaya mengubah apa pun menjadi komoditas (Mosco, 2009).

Komodifikasi banyak terjadi pada budaya populer. Fedorak (2009) memaparkan bahwa ada dua pendekatan terhadap budaya populer: teori budaya massa dan teori populis. Teori budaya massa menyatakan bahwa budaya tinggi, seperti opera dan musik klasik, lebih bernilai dan mencerahkan dan yang disebut budaya populer adalah milik "massa tanpa pikiran" yang menerima dan menyerapnya begitu saja tanpa bertanya. Adapun teori populis menimbang budaya populer sebagai pengejaran yang menggairahkan yang menawarkan hadiah intrinsik dan ekstrinsik dan sebuah peluang untuk lari dari ketegangan hidup sehari-hari.

Adapun Ariel Heryanto (2008) mendefinisikan budaya populer atau budaya pop untuk merujuk pada berbagai genre praktik komunikasi yang tersebar luas secara mencolok pada sejumlah besar orang "biasa", atau oleh orang-orang seperti itu, atau kombinasi keduanya. Kategori pertama (untuk masyarakat) mengacu pada pesan-pesan yang diproduksi secara massal (termasuk musik, film, dan televisi) dan praktik penandaan. Kategori kedua (oleh masyarakat) termasuk praktik komunikasi nonindustrial, yang relatif independen, yang beredar melalui berbagai 
cara (acara publik, parade, festival), yang sering, tetapi tidak selalu, dalam oposisi atau alternatif untuk komoditas hiburan yang diproduksi secara massal. Menurut Heryanto (2008), budaya populer seringkali dimaksudkan terutama untuk menjadi objek hiburan dan komoditas.

Dengan menimbang definisi di atas, maka dangdut termasuk bentuk budaya populer. Andrew N. Weintraub (2010) menawarkan pendekatan dengan melihat dangdut sebagaimana adanya. Dangdut, menurut Weintraub, adalah genre musik populer yang dimediasi massa yang berkembang di Jakarta pada awal 1970-an. Musik Indonesia paling populer ini adalah jenis musik paling hibrida, campuran unsur-unsur musik Melayu, Arab, dan India dengan bentuk-bentuk populer Amerika, Latin, dan Eropa. Instrumen dasarnya adalah gitar, drum, keyboard elektronik, mandolin, tambur serta suara khas gendang dan suling.

Weintraub (2006) menggambarkan dangdut, yang namanya dipungut dari suara drum "dang" dan "dut", pada mulanya musik rakyat. Dangdut mencerminkan keinginan dan aspirasi "rakyat", terutama yang menempati strata bawah dalam struktur politik dan ekonomi: rakyat kecil, rakyat jelata, rakyat jembel, golongan bawah, kaum marginal, pinggiran, kelas menengah ke bawah.

Pada akhir 1980-an, penonton dangdut mulai berubah. Musik ini mulai menjangkau kelas menengah dan elite lewat televisi komersial pada 1990-an. Pergeseran ini geografi sosial ini, menurut Weintraub (2006), menempatkan dangdut dalam sebuah posisi sosial yang kuat. Dia kini juga dirayakan sebagai musik nasional oleh militer dan pemerintah.

Pada 1990-an, dangdut masuk ke ranah industri melalui siaran televisi swasta seperti Televisi Pendidikan Indonesia (TPI). Pada masa itu pula Kopi Dangdut dirayakan sebagai album terpopuler di Jepang, yang menunjukkan menguatnya pasar global dangdut.

Eksperimen program dangdut di televisi telah dimulai sejak lama. MTV Asia, misalnya, pernah membuat acara Salam Dangdut yang disiarkan pada 1999 (Weintraub A. N., 2006).

Komodifikasi dangdut sebagai budaya populer ini terus marak hingga kini. Dangdut adalah bagian lokal dari industri musik pop global. Musiknya, yang dipengaruhi oleh nada musik Melayu populer dan lagu-lagu film India, dan kemudian oleh musik pop dan rock Barat, berkaitan erat dengan munculnya industri hiburan dan media massa elektronik di Indonesia pasca-kolonial (David, 2014).

Komodifikasi paling nyata terlihat adalah masuknya dangdut ke dalam industri musik, yang dimulai melalui industri rekaman dan radio. Menurut data Asosiasi Industri Rekaman Indonesia (ASIRI), ketika bisnis musik di Indonesia berjaya di Asia Tenggara pada 1990an, 35 persen pasar musik Indonesia adalah dangdut (Sen \& Hill, 2000).

Ketika industri televisi berkembang, televisi pun memberi ruang bagi musik ini. Televisi Pendidikan Indonesia (TPI), yang kini berubah menjadi MNCTV, adalah televisi pertama yang getol mengangkat dangdut di era 1990an. Tapi, kala itu dangdut masih dibebani asosiasi simbolik sebagai musik kelas bawah dan bahkan orang kelas menengah dan atas memberi nama yang merendahkan kepada TPI sebagai "Televisi Pembantu Indonesia" karena penggemarnya yang banyak dari kalangan perempuan pekerja domestik (Weintraub A. N., 2010). Namun, dalam dekade belakangan ini pun, musik dangdut masih digemari masyarakat lapisan bawah, seperti tampak dari pertunjukan rutin musik dangdut di Purawisata dan Cafe Takasimura di Yogyakarta (Astuti, 2017).

Saat ajang pencarian bakat (talent show) mulai populer di dunia dalam satu dekade belakangan ini, televisi juga ramai-ramai mengembangkan acara serupa, seperti Indonesian Idol. Musik dangdut pun mendapat tempat melalui, misalnya, Konser Dangdut Indonesia (KDI) di TPI dan Liga Dangdut Indonesia (LIDA) di Indosiar Visual Mandiri (Indosiar). 
Program pencarian bakat penyanyi di televisi ini adalah bentuk komodifikasi yang populer kembali di masa kini (Redden, 2010). Acara-acara itu mengisahkan keberuntungan para kontestan untuk menjadi selebriti yang berpotensi untuk dipasarkan melalui berbagai produk meskipun tak ada jaminan mereka berhasil mencapainya. Komodifikasi ini melibatkan organisasi yang rumit yang menghubungkan kontestan, media, penonton, dan pasar secara luas. Ini terjadi, misalnya, pada acara $X$ Factor dan American Idol di Amerika Serikat.

Di Indonesia, komodifikasi di dunia pertelevisian sudah banyak diteliti. Asri Nuraeni dan Rona Mentari, misalnya, meneliti komodifikasi di ajang pencarian bakat Dai Muda Pilihan ANTV, kontes pencarian dai dan diah berusia 17-25 tahun yang diadakan oleh $A N T V$. Peneliti memaparkan terjadinya modifikasi konten dan pekerja pada acara tersebut (Nuraeni \& Mentari, 2015).

Nur Ruli Febriyanti dan Andi Faisal Bakti meneliti komodifikasi dan spasialisasi di grup media Transmedia. Mereka menemukan bahwa komodifikasi pekerja terjadi melalui strategi pencerminan (mirroring), ketika satu pekerja bisa merangkap dua jabatan di dua stasiun televisi yang berbeda dalam satu grup (Febriyanti \& Bakti, 2017).

Komodifikasi kemiskinan adalah salah satu tema yang banyak diteliti. Beberapa penelitian itu antara lain mengenai Mikrofon Pelunas Hutang di Indosiar (Mumpuni, 2018) (Hasan, 2018), Orang Pinggiran di Trans 7 (Nisa, 2014), dan Bedah Rumah (Widodo, 2010). Adapun Saiful Totona membandingkan komodifikasi kemiskinan dalam tiga tayangan, yakni Duit Kaget di RCTI, Tukar Nasib di SCTV dan Jika Aku Menjadi di Trans TV (Totona, 2010)

Meskipun musik dangdut sudah muncul lama, penelitian mengenai komodifikasi pada acara dangdut di televisi masih terbatas. Agus Rianto (2013) meneliti "komodifikasi goyang" yang terjadi dalam pertunjukan dangdut. Baginya, tayangan dangdut di televisi telah mendistorsi dunia sosial dengan membesarbesarkan citra tertentu. Dia mencontohkan bagaimana kamera mengambil bagian-bagian tubuh tertentu pada penyanyi dangdut wanita untuk menjadi tontonan publik.

Komodifikasi tubuh dalam pertunjukan dangdut juga diteliti oleh Rizky Hafiz Chaniago dan Fuziah Kartini Hassan Basria. Mereka menemukan bahwa identitas penyanyi dangdut, seperti Inul Daratista, terletak pada goyangan yang seksi dan senyuman yang sensual. (Chaniago \& Basria, 2012).

Meskipun tak secara eksplisit membahas komodifikasi musik dangdut, Gabriela Deasyntya Kaloka Putri (2018) menunjukkan bagaimana perempuan penonton dangdut harus berhati-hati dalam menampilkan identitas musik mereka. Mereka lebih memilih ruang yang intim dan tertutup untuk menunjukkan kesenangan mereka terhadap dangdut.

Penelitian S. A. Billah (2019) menyoroti bagaimana Indosiar memanfaatkan multiplatform dengan menayangkan juga acara LIDA di Youtube. Meski tidak menyebut secara eksplisit, strategi Indosiar ini sebenarnya termasuk bentuk komodifikasi di acara dangdut.

Della Andiani dan Rini Rinawati (2017) menemukan bahwa kontes penyanyi dangdut D'Academy merepresentasikan dangdut menjadi lebih kontemporer melalui kode-kode sosial John Fiske, seperti cara berpakaian dan megahnya panggung. Adapun Zafirah Quroatun (2016) melihat bahwa dangdut kontemporer telah membentuk "homogenisasi cita rasa" untuk tujuan "komersialisasi" produk budaya.

Dengan melihat hal-hal di atas, penelitian ini hendak menyoroti bagaimana komodifikasi terjadi dalam ajang pencarian bakat penyanyi musik dangdut Liga Dangdut Indonesia yang diselenggarakan Indosiar. Peneliti hendak mengidentifikasi bentuk-bentuk komodifikasi apa saja yang terjadi dalam program tersebut.

Penelitian terhadap budaya dangdut sebenarnya merupakan kajian terhadap ceritacerita tentang negara-bangsa modern Indonesia. 
Sebagaimana ditunjukkan Weintraub (2006), dangdut adalah ranah ekonomi politik tempat pertarungan makna-makna termediasi tentang hubungan-hubungan sosial di masyarakat moden Indonesia.

Penelitian ini akan melengkapi berbagai penelitian mengenai budaya populer dangdut. Dengan begitu, masyarakat akademis, juga masyarakat umum, akan mendapat gambaran yang lebih lengkap mengenai hubungan budaya dangdut dan media massa, khususnya televisi, di alam Indonesia masa kini.

Untuk melihat proses komodifikasi yang terjadi, penelitian ini akan menggunakan pendekatan ekonomi politik komunikasi. Vincent Mosco menggariskan bahwa ada tiga jenis komodifikasi yang mungkin terjadi, yakni komodifikasi pada isi media, khalayak (audience), dan pekerja. (Mosco, 2009). Komodifikasi isi adalah proses komodifikasi dalam komunikasi berupa perubahan pesanpesan menjadi produk yang dapat dipasarkan (Mosco, 2009). Dalam proses ini, hubungan antara status komoditas isi dan maknanya menjadi penting karena, selain dapat menghasilkan nilai lebih, dia mengandung simbol dan citra yang maknanya turut membentuk kesadaran (Mosco, 2009)

Adapun komodifikasi pekerja berkaitan dengan tenaga kerja. Menurut Harry Braverman (1998), tenaga kerja terbentuk dari kesatuan konsepsi, atau kemampuan/keterampilan untuk membayangkan dan merancang, dan eksekusi, atau kekuatan untuk melaksanakannya. Komodifikasi pekerja terjadi ketika pemilik modal berusaha memisahkan konsepsi dari eksekusi agar dapat mengatur kembali proses kerja supaya sesuai dengan distribusi keterampilan dan tenaga baru ini pada proses produksi.

Komodifikasi khalayak terjadi ketika media massa memandang khalayak atau audiens sebagai komoditas. Televisi, misalnya, memproduksi sebuah acara yang menarik perhatian orang untuk menonton, yang pada gilirannya menarik pengiklan untuk memasang iklannya. Bagi Dallas Smythe, khalayak justru komoditas utama dari media massa karena yang dijual media sesungguhnya bukanlah program (yang bisa diperoleh penonton secara gratis) tapi penonton yang setia pada program itu yang kemudian diserahkan ke pemasang iklan (Fuchs, 2014).

Christian Fuchs lalu memperkenalkan teori komodifikasi pekerja digital untuk melihat perkembangan dunia digital masa kini. Menurut Fuchs, pekerja digital lebih luas dari pekerja-audiens dalam komodifikasi khalayak karena meliputi seluruh pekerja yang berperan dalam jaringan transnasional media digital, dari perakit perangkat keras, produser konten, hingga konsumen pengguna media (Fuchs, 2017). Dalam konteks khalayak, komodifikasi pekerja digital, antara lain, terjadi ketika penonton turut berpartisipasi dengan memproduksi konten di media sosial yang berhubungan dengan media tersebut. Alvin Toffler (1980) menyebutnya "prosumen", untuk memprediksi jumbuhnya peran konsumen dan produsen dalam ekonomi pasar masa depan. Dalam penelitian mengenai Facebook, Tiziana Terranova (2000) menyebutnya "pekerja gratis" ("free labor") karena pekerja lebih memahaminya sebagai kegiatan bermain-main.

Penelitian ini hendak mengidentifikasi komodifikasi pada isi media, khalayak, dan pekerja menurut teori Mosco pada ajang pencarian bakat penyanyi dangdut LIDA Indosiar. Peneliti juga menambahkan teori Fuchs tentang komodifikasi pekerja digital untuk melihat fenomena mutakhir ekonomi politik komunikasi di era digital.

\section{METODOLOGI}

Penelitian ini merupakan penelitian kualitatif dengan paradigma interpretif. Menurut Creswell (2007), paradigma interpretif menyediakan sebuah lensa luas atau perspektif terhadap semua aspek proyek riset kualitatitif. Masalah dan pertanyaan riset yang dieksplorasi ditujukan untuk memahami isu-isu atau topiktopik spesifik, seperti hirarki, hegemoni, dan 
relasi kuasa yang timpang.

Penelitian ini dilakukan dengan metode studi kasus. John Creswell (2007) menyatakan bahwa riset studi kasus mengeksplorasi satu atau lebih sistem kontemporer tertentu di kehidupan nyata atau suatu kasus di suatu waktu melalui penghimpunan data mendalam dan rinci dari berbagai sumber informasi, seperti observasi, wawancara, dan laporan. Peneliti lalu memaparkan deskripsi kasus dan tema-tema berbasis kasus tersebut.

Creswell menguraikan lima tahap dalam penelitian studi kasus (Creswell, 2007). Pada tahap pertama, penelitian mempelajari masalah yang hendak diteliti. Untuk mendalami masalah komodifikasi dalam dangdut, peneliti meninjau berbagai studi mengenai dangdut di jurnal penelitian maupun buku mengenai hal tersebut.

Pada tahap kedua, peneliti memutuskan tujuan penelitian dan memilih kasus yang hendak diteliti. Dalam hal ini, peneliti memilih acara LIDA Indosiar sebagai kasus.

Di tahap ketiga, peneliti menghimpun sebanyak mungkin data dari berbagai sumber. Peneliti menggali informasi mengenai dangdut dan acara dangdut Indosiar dari berbagai berita media massa, dokumen, dan referensi. Peneliti juga melakukan wawancara mendalam dengan pengelola LIDA. Peneliti juga menonton acara tersebut di televisi dan meninjau kembali rekaman video acara tersebut serta menonton langsung di studio Indosiar.

Pada tahap keempat, peneliti menganalisa berbagai data dan menyusun suatu deskripsi kasus yang diintegrasikan dengan tema dan informasi kontekstual. Latar belakang, konsep, sejarah, dan penyelenggaraan acara LIDA menjadi penting diperiksa untuk memetakan kasus tersebut. Dengan dibantu berbagai teori dan pendekatan, peneliti menyoroti kasuskasus yang relevan dan mentransendensikannya sebagai suatu fenomena.

Tahap terakhir adalah pengambilan kesimpulan dan pelajaran yang diambil dari kasus yang kemudian dipaparkan dalam laporan. Penulisan laporannya melibatkan suatu proses refleksi atas kasus tersebut.

\section{HASIL DAN PEMBAHASAN}

Liga Dangdut Indonesia (LIDA) adalah salah satu kontes pencarian bakat (talent show) penyanyi dangdut di stasiun televisi Indosiar Visual Mandiri (Indosiar) dan dibanjiri oleh puluhan ribu pendaftar dari seluruh Indonesia. Jenis acara ini sering disebut juga reality television show karena menampilkan pertunjukan yang tanpa skrip di televisi. Pada musim pertama yang digelar pada 2018, kontes ini meraih Piagam Penghargaan Program Pencarian Bakat dengan Peserta dari Provinsi Terbanyak dari Museum Rekor Dunia Indonesia. Dengan audisi di masing-masing provinsi, kontes akan memilih tiga juara yang akan memperebutkan hadiah total $\mathrm{Rp} 1$ miliar dan piala bergilir sesuai provinsi asal pemenang (Sundari, 2018).

Indosiar belum pernah mengungkap seberapa besar sumbangan acara ajang pencarian bakatnya, khususnya LIDA, terhadap pendapatannya. Namun, MNC memaparkan bahwa acara ajang pencarian bakatnya menghasilkan lebih dari $80 \%$ pendapatan (revenue) per satu jam siaran, melampaui drama seri (41\%) dan infotainment (32\%) (MNC, 2020). Acara MNC itu antara lain adalah Indonesian Idol dan Idol Junior.

Ajang pencarian bakat adalah salah satu jenis hiburan andalan televisi untuk meraup pendapatan melalui iklan dan sumber lain. RCTI dan Indosiar (IVM) bersaing ketat dalam jenis program ini. Laporan PT Surya Citra Media Tbk menunjukkan bahwa sepanjang tahun 2017, Indosiar mendominasi acara pencarian bakat dengan 15 dari 20 program (PT Surya Citra Media Tbk, 2017). Sebagian besar program itu adalah acara D'Academy, ajang pencarian bakat penyanyi dangdut yang mendahului LIDA. Sisanya dipegang oleh RCTI. (Lihat Tabel 1). 
Tabel 1. Top 20 Talent Search Programs of 2017

\begin{tabular}{cllll}
\hline No. & Program & Channel & TVR & Share \\
\hline 1 & Kemenangan D4 Academy 2017 & IVM & 4,5 & 25,0 \\
2 & Grand Final 2017 & IVM & 3,7 & 19,0 \\
3 & Grand Final SCA3 2017 & IVM & 3,4 & 17,3 \\
4 & Audisi 2017 & IVM & 3,0 & 14,6 \\
5 & DA-4 Nominasi & IVM & 3,0 & 15,7 \\
6 & Parade 2017 & IVM & 2,9 & 14,2 \\
7 & Duel & RCTI & 2,9 & 19,0 \\
8 & 5 Star D4A & IVM & 2,8 & 16,1 \\
9 & Wild Card & IVM & 2,8 & 14,3 \\
10 & Launching Dangdut-A4 & IVM & 2,7 & 14,3 \\
11 & Grand Final RSI & RCTI & 2,7 & 19,1 \\
12 & Live Aud & RCTI & 2,5 & 17,1 \\
13 & Super Semi Final & RCTI & 2,4 & 18,5 \\
14 & RSI Super Stage & RCTI & 2,4 & 16,6 \\
15 & DA Asia 3 & IVM & 2,4 & 13,4 \\
16 & Wild Card 5 Besar & IVM & 2,4 & 12,5 \\
17 & Result DAS2 2016(R) & IVM & 2,4 & 12,1 \\
18 & Pilih-pilih 4 & IVM & 2,4 & 11,8 \\
19 & Grand FInal BP4 2017 & IVM & 2,3 & 14,6 \\
20 & Favorit Sosial Media 2017 & IVM & 2,3 & 12,4 \\
\hline
\end{tabular}

Sumber: PT Surya Media Tbk (2017)

Siaran pencarian bakat ini berlangsung hampir setiap hari pada jam utama (prime time). Durasinya panjang, sekitar 3-4 jam, yang dimulai pada pukul 19.00. Bahkan, siaran D'Academy bisa sampai 5-6 jam.

Dari Tabel 1 tampak bahwa Indosiar menarik keuntungan besar dari program pencarian bakat dangdut, baik dari rating (TVR) maupun audience share. Besarnya dua faktor itu berpengaruh pada perolehan iklan karena pemasang iklan akan tergiur pada acara yang menarik banyak penonton sehingga iklannya pun akan disaksikan banyak orang.

Dalam bisnis pertelevisian, pengiklan akan memasang iklannya berdasarkan rating atau audience share televisi tersebut. Berdasarkan data Nielsen, per Februari 2019, grup Media Nusantara Citra (MNC) duduk di peringkat pertama dengan audience share $35,3 \%$ pada alltime, diikuti Surya Citra Media (SCM) dengan 31,5\%, Visi Media Asia (VIVA) dengan 15,4\%, dan Trans Media dengan 13,8\%. (DBS Group Research, 2019). Namun, SCM menguasai audience share pada prime-time sebesar 33,2\%, khususnya anak usahanya, Surya Citra Televisi (SCTV), yang memegang 18,8\% dari audience share tersebut. Adapun 14,4\% audience share pada prime-time dipegang Indosiar Visual Mandiri, anak usaha SCM. Secara khusus, DBS Group Research mencatat bahwa Indosiar mengalami peningkatan audience share pada prime-time dari bulan-bulan sebelumnya setelah menayangkan Liga Dangdut Indonesia. (DBS Group Research, 2019)

Indosiar secara konsisten mengangkat musik dangdut dalam acara pencarian bakatnya. Konsep acaranya sejak awal digagas oleh Direktur Programming SCM Harsiwi Achmad, yang menggawangi program dan produksi siaran di SCTV dan Indosiar. Indosiar memulainya dengan Dangdut Academy (D'Academy) pada 2014. Pada mulanya acara ini hanya ditujukan untuk warga Indonesia. Tapi, dalam perkembangannya, acara ini meluas hingga ke tingkat Asia dengan nama D’Academy Asia sejak April 2016 dengan peserta dari negara di Asia Tenggara, termasuk Indonesia, Malaysia, Singapura, dan Thailand. Acara ini kemudian dibagi dalam dua jalur yang berjalan paralel. Kontes tingkat nasional melalui D'Academy dan tingkat internasional melalui D'Academy Asia.

Sejak Januari 2018, D'Academy beralih rupa menjadi LIDA. Audisi LIDA digelar di 34 provinsi di Indonesia dan menghasilkan 80 duta terpilih yang mewakili provinsinya masing-masing untuk maju berlaga di babak utama yang digelar di Jakarta (Merdekawan, 2019).

Indosiar menghadirkan penyanyi dangdut papan atas untuk menjadi juri. Pada 2018, juri yang terlibat adalah Elvy Sukaesih, Rita Sugiarto, Iyeth Bustami, Inul Daratista, Nassar, Zaskia Gotik dan Samuel Wattimena (Sundari, 2018). Pada 2019, Indosiar menghadirkan Soimah, Nassar, Inul Daratista, Dewi Perssik, Zaskia Gotik, Rita Sugiarto dan Erie Suzan sebagai juri (Purnomo, 2019).

Penentuan skor bersumber dari tiga hal, yaitu penilaian panel provinsi dan lima dewan juri yang terdiri dari empat juri musisi dangdut dan satu juri tamu yang bukan dari kalangan dangdut, juga dukungan pemirsa lewat pesan singkat (SMS). Panel provinsi memiliki bobot 5 persen, dewan juri memiliki bobot 20 persen, serta SMS dan vote pemirsa memiliki 
bobot paling besar, yakni 75 persen. Di akhir acara, ketiga elemen penilaian tersebut akan digabungkan untuk menentukan siapa peserta yang menang (Gita, 2019).

Kontes LIDA memperebutkan hadiah utama berupa uang tunai dengan total $\mathrm{Rp} 1$ miliar. Rinciannya, Rp 500 juta untuk pemenang pertama, Rp 300 juta untuk pemenang kedua, dan Rp 200 juta bagi pemenang ketiga. Kontes juga memperebutkan piala bergilir yang akan diberikan kepada provinsi asal juara pertama. Piala ini berlaku selama setahun hingga LIDA musim berikutnya beroleh pemenang baru. Peraih piala bergilir LIDA 2018 adalah Sulawesi Selatan dan Aceh pada LIDA 2019 (Sundari, 2018). Hingga saat ini kontes tersebut telah memasuki musim ketiga. LIDA 2020 telah memasuki tahap babak utama yang ditayangkan setiap hari pukul 21.00 WIB di Indosiar.

Popularitas LIDA telah melahirkan idolaidola baru dangdut. Mereka adalah orang biasa yang berbakat menyanyi dangdut atau penyanyi dangdut pemula yang baru meniti karir di kampung halamannya yang kemudian mencapai ketenaran melalui kontes pencarian bakat di televisi.

Ciri orang biasa atau penyanyi pemula ini penting. Dia menawarkan harapan bagi siapa saja untuk menjadi idola dangdut. Rincian latar belakang kontestan sebagai orang kebanyakan, seperti petugas keamanan kantor atau penyanyi kampung yang punya gubuk reyot, diangkat sebagai bagian dari kisah sukses yang nantinya dipamerkan di sela-sela acara LIDA. Misalnya kisah Selfi Soppeng, juara pertama LIDA sesi pertama. Media-media memberitakan bagaimana Selfi lahir dari masyarakat lapisan bawah. Dia hanya penyanyi orkes kampung, ayahnya bekerja sebagai pengemudi becak motor, dan ibunya tukang cuci keliling. (Arbi, 2019). Cerita tentang orang-orang yang mengalami perubahan hidup dari bukan siapasiapa menjadi seseorang, from zero to hero, ini menjadi fragmen-fragmen dari drama kelahiran sang idola.
Sekali kontestan lolos di ajang pencarian bakat, statusnya langsung berubah menjadi selebriti (Setyorini, 2019). Mereka kini disejajarkan dengan penyanyi tenar seperti Iwan Fals, Agnez Mo, dan Rossa (Dzikry, 2020). Istilah "selebriti” ini mencakup semua orang yang dianggap terkenal, dari bintang film dan youtuber hingga tokoh politik dan pejabat pemerintah (Rojek, 2001). Kesamaan ciri di antara mereka semua adalah ketenaran, yang merupakan hasil dari strategi pemberitaan media hiburan.

Masyarakat mengkonfirmasi status selebriti itu dengan memandang para kontestan LIDA sebagai idola yang patut dipuja. Ketika dua kontestan LIDA, Eva Yolanda dan Hamid Aan, pulang ke kampung halamannya di Desa Lando, Kecamatan Terara, Lombok Timur, pada 5 April 2020, ribuan orang berdesakdesakan menyambut mereka di Bandar Udara Mali, Alor, Nusa Tenggara Timur. Padahal, Eva sebenarnya sudah kalah dalam dalam kontes LIDA sehari sebelumnya (Iswara, 2020)

Selebriti dari kalangan orang biasa ini tergolong "selebriti karena prestasi" (achieved celebrity), seperti yang didefinisikan oleh Chris Rojek (2001). Rojek menyatakan bahwa sebagian achieved celebrity ini merupakan hasil dari representasi terkonsentrasi dari seseorang sebagai hal yang penting atau luar biasa oleh impresario budaya. Impresario budaya adalah para perantara budaya (cultural intermediaries) yang mengelola rantai tarik-menarik antara penampil dan penonton untuk mendapatkan keuntungan. Mereka menghadirkan selebriti dalam istilah-istilah sensasional untuk memaksimalkan daya tarik mereka (Rojek, 2001).

Di LIDA, impresario budaya ini adalah tim produksi Indosiar. Tim pengelola LIDA merancang panggung pertunjukan secara mewah dan megah untuk menampilkan wajah yang mereka sebut sebagai "dangdut kelas atas". Gaun para kontestan juga disiapkan sedemikian rupa sehingga akan tampak mewah dengan melibatkan sejumlah perancang busana 
Indonesia, seperti Dian Pelangi dan Oki Setiana Dewi.

Ada pula 13 juru kamera, enam tenaga kreatif, lima tenaga properti dan efek khusus, dan 10 wardrobe. Mereka merancang panggung megah untuk menampilkan wajah "dangdut kelas atas" dengan pengemasan yang sangat luar biasa dari sisi tata panggung, lighting, konsep dan lainnya. "Kami ingin menjadikan musik dangdut naik kelas dan menyebarkan musik dangdut di Asia," kata Ade Rianti (wawancara pribadi, 13 November 2018).

Sensasionalitas dalam LIDA terlihat dalam upaya Indosiar mengangkat drama-drama kehidupan para kontestan dan juaranya. Ini misalnya dengan mendramatisasi hal-hal yang sebetulnya biasa saja, seperti cerita para kontestan yang jatuh cinta selama kontes berlangsung atau kisah cinta hingga pernikahan Fomal dan Fikoh (Nugroho, 2020)

Kemenangan di ajang LIDA telah menjadi suatu gengsi tertentu bagi peserta dan daerah asal peserta. Dinas Pariwisata Lampung, misalnya, menganggap kekalahan peserta dari daerahnya bukan hanya persoalan kekalahan kontestan biasa tapi urusan pemerintah meskipun tak ada hubungan formal antara peserta tersebut dengan pemerintah (Iqbal, 2018 ).

Kontes LIDA telah berkembang menjadi suatu realitas yang menawarkan nilai-nilai tertentu bagi partisipannya. Mengikuti LIDA bukan semata perkara berlomba untuk menjadi pemenang kontes menyanyi dangdut dan kemudian terkenal tapi menjadi bagian dari suatu realitas baru yang mengandung seperangkat nilai yang dibangun melalui pencitraan dangdut sebagai budaya yang luhur dan bermutu tinggi. Produser D'Academy Asia, Ade Rianti, menyatakan pentingnya musik dangdut sebagai kebudayaan Indonesia yang harus dilestarikan. "Dangdut adalah musik yang tidak bisa dipandang sebelah mata, bukan musik murahan, dan bukan musik kampung," kata Ade (wawancara pribadi, 10 November 2018). Dia memuji mutu musik dangdut karena terbukti bisa diangkat ke ajang Asia dan bisa menyatukan rakyat Indonesia. Bahkan Ade meyakini bahwa dangdut adalah budaya yang luhur dan harus dijunjung tinggi. Dia juga mencemaskan bahwa budaya ini suatu saat nanti akan punah bila tidak dilestarikan.

Upaya membangun citra dangdut sebagai budaya kelas atas dan luhur yang mampu bersaing di aras global ini dilakukan dengan mengangkat dangdut ke level regional melalui D'Academy Asia. Kemenangan kontestan Indonesia di ajang ini membuat mereka merasa berjaya di level yang lebih tinggi, yakni di tingkat Asia, meskipun masih diragukan bahwa dangdut memang telah populer di Asia dan apakah para kontestan cukup mewakili untuk disebut Asia. Legitimasi terhadap klaim ini dilakukan antara lain dengan melibatkan peserta dan juri yang mewakili negara-negara di Asia Tenggara, seperti Singapura, Malaysia, dan Thailand.

Dari pemantauan yang dilakukan sejak 2018 hingga Januari 2020, peneliti menemukan bahwa kontes pencarian bakat penyanyi dangdut LIDA telah mengalami komodifikasi tertentu sejak dari tahap penjaringan peserta atau kontestan. Komodifikasi itu terjadi baik dalam komodifikasi isi siaran, khalayak, maupun pekerja. Namun, dalam konteks kehadiran media baru, termasuk media sosial, komodifikasi itu menjadi bentuk baru sebagai varian dari bentuk komodifikasi yang diuraikan Mosco.

Komodifikasi isi terjadi ketika Indosiar mengolah konten LIDA ke dalam berbagai bentuk. Siaran LIDA dilakukan secara real time dengan menayangkan secara langsung setiap tahap kontes, dari audisi, babak penyisihan, hingga final. Tayangan itu disiarkan sekitar 3-5 jam setiap hari, bahkan bisa sampai 6-7 jam pada babak final. Panjangnya durasi membuat penghasilan iklan dari acara ini meningkat.

Indosiar tak membuat acara promosi khusus tapi menggerakkan tim promosi grup Elang Mahkota Teknologi (EMTEK), induk perusahaan Indosiar. Tim itu adalah situs layanan penyimpanan video Vidio dan media 
online KapanLagi.com. Vidio menayangkan acara LIDA secara langsung tapi juga menyediakan berbagai rekaman potongan acara itu, terutama bagian-bagian yang paling penting, dramatis, dan menghebohkan.

Berbagai kejadian dan isu di LIDA juga diamplifikasi melalui berita-berita di KapanLagi.com, seperti potongan momen penobatan Fauzul Abadi sebagai penyanyi dangdut terbaik se-Asia di ajang Dangdut Academy Asia 5 (Nugraha, 2019), terpilihnya Tiyara Ramadhani atau Rara sebagai host baru LIDA 2020 (Nugraha, 2020a), dan rencana pernikahan Fomalhaut Zamel dan Rofikoh Isnaini, salah satu kontestan LIDA 2019 (Nugraha, 2020b).

Dengan cara ini, Indosiar, melalui EMTEK, tetap meraup pendapatan bahkan setelah siaran LIDA selesai. Penempatan rekaman di Vidio dan Youtube juga membuat pemasukan dari iklan di video itu mengalir terus selama rekaman tetap terpajang dan penonton tetap mengunjunginya. Strategi serupa juga dilakukan RCTI dalam ajang pencarian bakat Indonesian Idol pada 2014 (Perdana, 2017). Hal ini menegaskan kecenderungan komodifikasi isi dalam industri televisi di Indonesia.

Komodifikasi penonton atau khalayak terjadi ketika peran khayak menyumbang rating atau audience share dari tayangan LIDA. Semakin banyak yang menonton, semakin besar LIDA berpeluang memperoleh iklan. Fakta bahwa Indosiar mendominasi acara pencarian bakat dengan 15 dari 20 program (lihat Tabel 1) menujukkan peran khalayak dalam pengumpulan audience share dan rating media tersebut yang berujung pada pendapatan iklan yang lebih besar.

Khalayak bahkan berpartisipasi dengan datang menonton langsung di Studio 5 Indosiar di Jalan Daan Mogot, Jakarta Barat. Penonton itu tak cuma yang mukim di Jakarta, tapi juga atang dari berbagai daerah. Penonton juga secara sukarela menggelar "nonton bareng" saat LIDA disiarkan. Misalnya, saat konser Top 6 grup 1 LIDA 2019 pada malam 24
April 2019, sejumlah orang menggelar acara menonton bersama, seperti di Maluku dan Sulawesi Selatan (Permana, 2019). Kehadiran penonton di studio dan nonton bareng ini jelas turut mendongkrak audience share LIDA.

Komodifikasi pekerja berlangsung ketika manajemen LIDA melibatkan departemen lain untuk mendukung kesuksesan acara terserbut. Salah satu yang diminta terlibat adalah departemen pemberitaan, yang sebenarnya selama ini bertugas memproduksi berita. Menurut produser Departemen Pemberitaan Indosiar, Jemmy Darusman, sumbangan itu berupa peliputan di balik acara LIDA, baik berupa berita teks, video, maupun siaran langsung (wawancara pribadi, 31 Mei 2020). Tim departemennya mengerjakan seluruh produksi tayangan, dari konsep, peliputan lapangan, hingga penyuntingan. Hasilnya tidak ditayangkan di acara departemen pemberitaan tapi menjadi sisipan di sela-sela program LIDA. Departemen ini pula yang mengerjakan acara siaran langsung nonton bareng di daerah asal peserta audisi yang berlangsung mulai pukul 17.00 hingga pukul 01.00 dini hari.

Pelibatan tim departemen pemberitaan itu juga mempengaruhi jam kerja karyawan di departemen tersebut. Normalnya karyawan bekerja sembilan jam dengan satu jam istirahat setiap hari. Ketika terlibat di LIDA, jam kerja mereka menjadi lebih lama, karena acara tersebut dapat berlangsung selama 13 jam, dari pukul 13.00 hingga 02.00 dini hari. Setelah acara siaran langsung pun biasanya tim tidak langsung pulang ke rumah tapi menggelar evaluasi terlebih dahulu, yang kadang berlangsung hingga pukul 05.00 untuk tim acara di Jakarta. Meski melebihi waktu kerja, pada kenyataannya karyawan tidak memperoleh hak pengganti lembur.

Karyawan Indosiar pun terlibat dalam promosi acara LIDA. Menurut Jemmy Darusman, tak ada kebijakan resmi manajemen agar karyawan turut mempromosikan acara itu tapi ada arahan informal dari Harsiwi Achmad agar para pegawai mempromosikan program 
LIDA lewat media sosial masing-masing (wawancara pribadi, 31 Mei 2020). Sesudah acara siaran langsung nonton bareng, misalnya, Jemmy biasa mengunggah foto dan video acara tersebut di akun Instagram pribadinya. Ia pun menyertakan catatan mengenai kesan dan pesannya kepada para peserta.

General Manager News Production Indosiar Ryan Wiedaryanto menguraikan beberapa alasan mengapa para pegawai membagikan informasi terkait LIDA atau program lainnya ke media sosial pribadi mereka (wawancara pribadi, 31 Mei 2020. Salah satunya, kata dia, adalah rasa kepemilikan terhadap program tersebut. Karyawan juga melakukan hal itu sekadar untuk lucu-lucuan atau keisengan belaka. Alasan lain adalah departemen. Ada kekhawatiran bila LIDA, yang memiliki rating share tinggi, akan anjlok bila ditangani penuh oleh Departemen Pemberitaan, yang menganggap program berita lebih serius ketimbang LIDA yang selalu diramaikan oleh nyanyian dan canda tawa.

Dalam acara pencarian bakat, kontestan juga menjadi pekerja dari media tersebut. Niat para kontestan untuk mengikuti kontes musik ini tidak harus untuk memenangi kompetisi tetapi kontrak (Cvetkovski, 2015). Dalam LIDA, iming-iming bagi kontestan pemenang adalah kontrak eksklusif dari Indosiar, yang dapat berupa menjadi host dan bernyanyi di berbagai acara Indosiar, termasuk di luar LIDA (Tribunjambi.com, 2019). Selain iklan dari acara LIDA, Indosiar mendapat keuntungan dari berbagai sumber, termasuk penyedia jasa telepon dan Internet saat pengguna mengirim pesan pendek untuk memilih kontestan (voting) dan tayangan ekstra. Model komersialisasi ini jamak dilakukan dalam acara ajang pencarian bakat penyanyi, seperti Idol di Amerika Serikat dan Norwegia (Kjus, 2009).

Komodifikasi pekerja pada kontestan LIDA melibatkan struktur rumit industri hiburan, khususnya musik dangdut. Ajang pencarian bakat adalah salah satu jalur untuk masuk ke dalam industri itu. Contohnya, Selfi
Yamma atau Selfi Soppeng, penyanyi asal Soppeng, Sulawesi Selatan, yang meraih juara pertama LIDA musim pertama sekaligus juara D'Academy Asia musim keempat pada 2018. Setelah menjadi juara, dia dikontrak Indosiar di berbagai acara televisi tersebut dan merilis single Menuju Terang (2018) produksi Trinity Optima Production dan Mati Rasa (2019) produksi 3D Entertainment. Dia juga bermain sinetron dan drama musikal (Aprilianti, 2019).

Komodifikasi pekerja digital atau prosumen terjadi saat khalayak turut berpartisipasi dalam media sosial Indosiar yang berkaitan dengan LIDA, misalnya dengan mengomentari dan membagi informasinya ke sesama pengguna media sosial. Akun instagram Indosiar (https:// www.instagram.com/indosiar), misalnya, diikuti oleh 2,2 juta pengguna. Akun itu sebagian besar berisi foto, video, dan pengumuman mengenai LIDA. Khalayak mengomentari konten tersebut dan banyak yang membaginya di akunnya pribadi maupun media sosial lain. Beberapa penggemar bahkan membuatkan laman khusus LIDA, seperti LIDA 2020 Indosiar (https://web.facebook.com/LIDA2020-Indosiar-111805873691405/) dan akun pemirsaindosiar (https://www.instagram.com/ pemirsaindosiar/) di Instagram dengan 204.000 pengikut yang isinya sepenuhnya membahas mengenai LIDA.

Dalam pandangan Marxian, komoditas mewujudkan hubungan-hubungan sosial dengan mempresentasikannya dalam sebuah bentuk yang membuatnya tampak alamiah. Sebuah produk tampak bagi kita sebagai komoditas dengan seperangkat nilai guna dan nilai tukar spesifik yang cenderung memistifikasi publik dalam memahami produk itu sebagai perwujudan dari pembagian kerja yang menciptakan tingkatan-tingkatan hubungan-hubungan produktif beserta dimensidimensi kelas, gender, bangsa, dan spasial (Mosco, 2009). Dalam analisa yang lebih dalam, komodifikasi menghasilkan fetisisme komoditas, yang tak hanya mewujudkan relasirelasi sosial dan menyembunyikan perjuangan 
atas nilai tapi mengambil alih kehidupan dan kekuasaan dari dirinya sendiri dari produsen dan konsumen (Mosco, 2009). Fetisisme komoditas terjadi ketika suatu produk seakan punya realitas sendiri dan menentukan hubungan antar-manusia. Secara sederhana ia bisa digambarkan sebagai "benda" yang memiliki suatu citra tertentu yang dipercaya membangun realitas "benda" tersebut. Contohnya, orang memandang secangkir kopi di Starbuck bukan lagi sekadar kopi yang bisa diminum tapi juga nilai-nilai gaya hidup yang melekat padanya.

Di LIDA, fetisisme komoditas terwujud melalui proses selebrifikasi yang melibatkan peran utama media massa dalam melahirkan budaya selebriti (Rojek, 2001). Selebrifikasi ini melahirkan idola-idola baru, fenomena yang juga ditemukan Penelope Coutas (2006) saat membahas Indonesian Idol di RCTI. Selebrifikasi itu melahirkan mistifikasi terhadap LIDA. Campur tangan pemerintah dalam kontes ini mengukuhkan LIDA sebagai komoditas yang mengalami mistifikasi.

Pandangan tim LIDA bahwa dangdut merupakan budaya yang bermutu, luhur, dan mengglobal mencerminkan suatu pandangan mengenai ancaman globalisasi budaya, khususnya melalui franchise pencarian bakat Idol yang mendunia. Prancis, misalnya, menanggapinya dengan membuat Nouvelle Star (Campaiola-Veen, 2012). Indonesia menanggapinya dengan Kontes Dangdut Indonesia (KDI) di MNCTV, yang mendahului D'Academy dan LIDA di Indosiar.

Meskipun banyak sarjana memandang implosi budaya sebagai reaksi terhadap globalisasi yang membuat bangsa-bangsa merasa terancam dan mengklaim kembali perbedaan budayanya, namun ajang pencarian bakat seperti Nouvelle Star menunjukkan sebaliknya: kemiripan dan hibridisasi (Campaiola-Veen, 2012). Hasil penelitian terhadap LIDA juga demikian. Komodifikasi pada LIDA tak jauh bedanya dengan acara American Idol dan Nouvelle Star, baik dalam mengeksploitasi drama di depan dan di belakang panggung maupun mengikat kontestan dan khalayak dalam jaringan industri hiburan.

Para selebriti dangdut LIDA tetaplah produk yang dipasarkan untuk mereka sendiri atau digunakan untuk memasarkan komoditas lain, yang merupakan potensi iklan menggiurkan bagi Indosiar. Komodifikasi dalam LIDA sebenarnya merupakan cara pemilik kapital untuk mengakumulasi modal semaksimal mungkin tapi menyembunyikan pertarungan nilai dan proses produksi di dalamnya. Dalam pengertian Antonio Gramsci (Hoare \& Sperber, 2016), pengemasan produk semacam ini merupakan upaya hegemoni, yang merupakan langkah pemilik modal untuk menghubungkan konsumen dengan produknya melalui operasioperasi sublim yang mengukuhkan status quo.

Dalam hal ini, hegemoni adalah formasi citra dan informasi untuk menghasilkan suatu peta akal sehat yang cukup persuasif bagi kebanyakan orang yang menyediakan koordinat-koordinat sosial dan budaya untuk menentukan sikap "alamiah" dari kehidupan sosial (Mosco, 2009). Hegemoni terhadap dangdut diarahkan pada persepsi dangdut sebagai budaya luhur, kelas atas, dan global tapi pada saat yang bersamaan menyembunyikan hubungan-hubungan sosial eksploitatif di dalamnya.

\section{SIMPULAN}

Ajang pencarian bakat penyanyi dangdut LIDA Indosiar telah mengalami komodifikasi isi, khalayak, pekerja, dan pekerja digital. Komodifikasi isi terjadi ketika Indosiar mengolah konten LIDA ke dalam berbagai bentuk yang memungkinkan mereka tetap meraup pendapatan bahkan setelah siaran LIDA selesai. Komodifikasi khalayak terjadi ketika penonton menyumbang rating atau audience share dari tayangan LIDA yang kemudian akan menarik lebih banyak iklan. Khalayak bahkan berpartisipasi dengan datang menonton langsung di studio. Komodifikasi pekerja berlangsung ketika karyawan di departemen pemberitaan dilibatkan untuk memperkaya 
isi LIDA melalui produksi berita dan siaran langsung meski harus bekerja melebihi waktu kerja hariannya tanpa memperoleh hak pengganti lembur. Meski tidak wajib, karyawan juga turut mempromosikan acara itu melalui media sosial pribadi masing-masing. Dalam hal komodifikasi pekerja digital, khalayak terlibat aktif menjadi prosumen saat berpartisipasi di media sosial Indosiar dan bahkan membuat akun khusus untuk penggemar LIDA. Proses komodifikasi ini berujung pada mistifikasi LIDA sebagai kontes bergengsi yang membangun citra dangdut sebagai budaya kelas atas, luhur, dan mengglobal. Hal ini terjadi melalui selebrifikasi yang melahirkan idolaidola dangdut baru sebagai selebriti. Namun, semua itu tetap menyembunyikan relasi-relasi sosial yang eksploitatif yang terjadi dalam proses komodifikasi di acara tersebut.

\section{DAFTAR PUSTAKA}

Andiani, D., \& Rinawati, R. (2017). Representasi dangdut kontemporer dalam acara D'Academy. Prosiding Manajemen Komunikasi , 3 (1), 149154.

Aprilianti, R. (2019, Mei 8). Mati rasa, Selfi Yamma rilis lagu sendu yang bikin baper. Dipetik Januari 24, 2020, dari Liputan6.com: https://www.liputan6. com/showbiz/read/3960076/mati-rasaselfi-yamma-rilis-lagu-sendu-yangbikin-baper

Arbi, A. (2019, 1 3). Selfi, sebelum juara hanya penyanyi elekton. Dipetik 62 , 2020, dari Radar Banten: https://www. radarbanten.co.id/selfi-sebelum-juarahanya-penyanyi-elekton/

Astuti, F. (2017). Musik dangdut bagi masyarakat lapisan bawah (Studi tentang apresiasi masyarakat lapisan bawah terhadap musik dangdut). (Skripsi, Fakultas Ilmu Sosial dan Ilmu Politik, Universitas Gadjah Mada). Diambil dari https://digilib.fisipol. ugm.ac.id/api/files/2c62f9d4-e8bb4d3e-a73f-5fe8e61b0f5a/MUSIK_ DANGDUT_full.pdf.

Billah, S. A. (2019). Kesiapan Indosiar dalam menghadapi era multiplatform \& konvergensi media. Jurnal Ilmu Komunikasi Andalan (JIKA), 2 (2).

Braverman, H. (1998). Labor and monopoly capital: the degradation of work in the twentieth century. New York: Monthly Review.

Campaiola-Veen, J. (2012). From affective to aesthetic economics: Globalization and the commodification of difference on French idol. Journal of International and Intercultural Communication , 5 (2), 89-105.

Chaniago, R. H., \& Basria, F. K. (2012). Citra wanita dalam perkembangan muzik dangdut di Indonesia. Jurnal Komunikasi: Malaysian Journal of Communication , 28 (2), 137-150.

Coutas, P. (2006). Fame, fortune, fantasi: Indonesian idol and the new celebrity. Asian Journal of Communication , 16 (4), 371-392.

Creswell, J. (2007). Qualitative inquiry and research design: Choosing among five approaches, second edition. California: Sage Publications.

Cvetkovski, T. (2015). The pop music idol and the spirit of charisma: Reality television talent shows in the digital economy of hope. London: Palgrave Macmillan.

David, B. (2014). Seductive pleasures, eluding subjectivities: Some thoughts on dangdut's ambiguous identity. Dalam B. Barendregt, Sonic modernities in the Malay world: A history of popular music, social distinction and novel lifestyles (1930s-2000s) (hal. 249-268). Leiden: Brill.

DBS Group Research. (2019). Indonesian media: February 2019 audience share. Dipetik Januari 20, 2020, dari https:// 
www.dbs.com.sg/vickers/en/research/ insights/190311_insights_indonesian_ media.page

Dentsu Aegis Network. (2019). Global ad spend forecasts, February 2019. Dipetik Januari 24, 2020, dari Dentsu Aegis Network: https://www. dentsuaegisnetwork.com/sg/en/reports/ ad_spend_jan_2019_pdf

Dzikry, A. (2020, 5 7). Emtek hadirkan 300 artis mulai dari Agnez Mo hingga Evan Dimas di Konser Amal Satu Indonesia. Dipetik 6 2, 2020, dari Bola.net: https://www.bola.net/lain_lain/emtekhadirkan-300-artis-mulai-dari-agnezmo-ariel-noh-hingga-evan-dimas-dikonser-amal-satu--253475.html

Febriyanti, N. R., \& Bakti, A. F. (2017). Kecenderungan komodifikasi dan spasialisasi pada Transmedia. CoverAge: Journal of Strategic Communication, 7 (2), 1-17.

Fedorak, S. (2009). Pop culture: The culture of everyday life. Ontario: University of Toronto Press Incorporated.

Fuchs, C. (2017). Dallas Smythe and digital labor. In R. Maxwell (Ed.), The Routledge companion to labor and media (pp. 108-127). New York: Routledge.

Fuchs, C. (2014). Digital labor and Karl Marx. New York: Routledge.

Gita, L. (2019, April 16). Konser top 12 grup 3 LIDA 2019: Siapa peserta yang tersenggol? Dipetik Januari 22, 2020, dari Liputan6.com: https://www. kapanlagi.com/dangdut/konser-top-12grup-3-lida-2019-siapa-peserta-yangtersenggol-95c81a.html

Hasan, S. (2018). Komodifikasi kemiskinan dalam acara reality show Mikrofon Pelunas Utang di Indosiar. (Skripsi, Fakultas Ilmu Sosial Dan Ilmu Politik, Universitas Hasanuddin). Dipetik dari http://digilib.unhas.ac.id/uploaded
files/temporary/DigitalCollection/ TZkMmU5NTQ2NjM1MTYyMQ==. pdf.

Heryanto, A. (2008). Popular culture in Indonesia: Fluid identities in postauthoritarian politics. New York: Routledge.

Hoare, G., \& Sperber, N. (2016). An introduction to Antonio Gramsci: his life, thought and legacy. New York: Bloomsbury Academic.

Iqbal, M. (2018 , 3 22). Dispar Lampung Beber Sebab Kekalahan Iqbal di LIDA Indosiar. Retrieved 5 30, 2020, from Rilis.Id: https://lampung.rilis.id/disparlampung-beber-sebab-kekalahan-iqbaldi-lida-indosiar

Iswara, N. (2020, 4 7). 2 finalis liga dangdut dikerumuni saat pulang di tengah corona, polisi kecolongan, ini kata Indosiar. Dipetik 62 , 2020, dari Tribunnewsmaker.com: https://newsmaker.tribunnews. com/2020/04/07/2-finalis-ligadangdut-dikerumuni-saat-pulang-ditengah-corona-polisi-kecolongan-inikata-indosia

Kjus, Y. (2009). Everyone needs idols: Reality television and transformations in media structure, production and output. European Journal of Communication (24), 287-304.

Merdekawan, G. (2019, Januari 3). Ini daftar lengkap 80 peserta yang lolos audisi Liga Dangdut 2. Dipetik Januari 22, 2020, dari Kapanlagi: https://www. kapanlagi.com/dangdut/ini-daftarlengkap-80-peserta-yang-lolos-audisiliga-dangdut-2-a5e217.html

MNC. (2020). PT Media Nusantara Citra: corporate update, january 2020. Jakarta: MNC.

Mosco, V. (2009). The political economy of communication 2nd edition. London: Sage Publications. 
Mumpuni, P. (2018). Komodifikasi kemiskinan pada reality show "Mikrofon Pelunas Hutang". Majalah Ilmiah Inspiratif , 3 (5).

Nisa, A. H. (2014). Komodifikasi kemiskinan dalam acara televisi: Analisis semiotika John Fiske mengenai komodifikasi kemiskinan dalam acara "Orang Pinggiran" yang ditayangkan di Trans 7. (Skripsi, Fakultas Ilmu Komunikasi, Universitas Islam Bandung). Dipetik dari http://repository.unisba.ac.id:8080/ xmlui/handle/123456789/248.

Nugraha, D. (2019, Desember 30). 10 momen juara Faul LIDA di konser kemenangan Dangdut Academy Asia 5. Dipetik Januari 24 , 2020, dari Kapanlagi.com: https://www.kapanlagi.com/dangdut/ berita-foto/10-momen-juara-faullida-di-konser-kemenangan-dangdutacademy-asi

Nugraha, D. (2020a, Januari 23). Jadi host baru LIDA 2020, hubungan asmara Rara langsung dibongkar Irfan Hakim. Dipetik Januari 24, 2020, dari Kapanlagi.com: https://www. kapanlagi.com/dangdut/jadi-host-barulida-2020-hubungan-asmara-raralangsung-dibongkar-irf

Nugraha, D. (2020b, Januari 23). Persiapan sudah 85 persen, Fomal dan Fikoh siap menikah bulan februari 2020. Dipetik Januari 24, 2020, dari Kapanlagi.com: https://www.kapanlagi.com/dangdut/ persiapan-sudah-85-persen-fomal-danfikoh-siap-menikah-bulan-f

Nugroho, D. W. (2020, 2 25). Berawal dari juri dan peserta, Fikoh LIDA tak menyangka kini menjadi istri Fomal. Dipetik 6 2, 2020, dari Kapanlagi.com: https://www.kapanlagi.com/dangdut/ berawal-dari-juri-dan-peserta-fikohlida-tak-menyangka-kini-menjadi-istridari-fomal-85dcda.html

Nuraeni,A., \& Mentari, R.(2015). Komodifikasi dai di televisi: Kajian ekonomi politik media. Komunikator , 5 (2), 70-82.

Perdana, D. D. (2017). Komodifikasi dalam tayangan televisi (Kajian terhadap program Indonesian Idol 2014). Jurnal Professional FIS UNIVED , 4 (1).

Permana, C. (2019, April 25). Serunya nonton bareng penampilan LIDA 2019 dari kampung halaman. Dipetik Januari 24 , 2020, dari Kapanlagi.com: https:// www.kapanlagi.com/dangdut/serunyanonton-bareng-penampilan-lida-2019dari-kampung-halaman-3f6eda.html

Pröschel, N. (2012). Commodification and culture: How can culture be economically used without selling it out? (Bachelor Thesis, Modul Vienna University). Diambil dari https://www. modul.ac.at/uploads/files/Theses/ Bachelor/Thesis-2012-ProeschelNatascha.pdf.

PT Surya Citra Media Tbk. (2017). Paparan publik 2017. Jakarta: PT Surya Citra Media Tbk.

Purnomo, S. (2019, Januari 14). Tampil beda LIDA 2019 akan lebih menghibur. Dipetik Januari 22, 2020, dari Liputan6. com: https:/www.liputan6.com/ showbiz/read/3870499/tampil-bedalida-2019-akan-lebih-menghibur

Putri, G. D. (2018). Negotiating dangdut sexuality: A glance through female audiences' music enjoyment. (Master thesis, Lund University). Diambil dari http://lup.lub.lu.se/student-papers/ record/8955918.

Quroatun, Z. (2016). Televisi dan industrialisasi budaya (Analisis wacana kritis terhadap acara musik dangdut D'T3rong Show). (Master Thesis, Universitas Gadjah Mada). Diambil dari http:// etd.repository.ugm.ac.id/home/detail_ pencarian/106461.

Redden, G. (2010). Learning to labour on the reality talent show. Media International 
Australia , 134 (1), 131-140.

Rianto, A. (2013). Goyang dangdut dan representasi ideologi di televisi. Komunika: Jurnal Dakwah dan Komunikasi , 7 (1).

Rojek, C. (2001). Celebrity. London: Reaktion Books.

Sen, K., \& Hill, D. (2000). Media, Culture and Politics in Indonesia. South Melbourne: Oxford University Press.

Setyorini, T. (2019, 11 23). 8 pasangan selebriti yang disebut cinlok di ajang pencarian bakat. Dipetik 62, 2020, dari Merdeka.com: https://www.merdeka. com/gaya/8-pasangan-selebriti-yangdisebut-cinlok-di-ajang-pencarianbakat.html

Sitanggang, D. (2015, Februari 6). Program baru di prime time, tarif iklan Trans $T V$ di atas Rp 50 juta. Dipetik Januari 22, 2020, dari SWA Online: https://swa. co.id/swa/trends/marketing/programbaru-di-prime-time-tarif-iklan-trans-tvdi-atas-rp50juta

Smith, A. (1977). An inquiry into the nature and causes of the wealth of nations. Chicago: University Of Chicago Press.

$\mathrm{Su}, \mathrm{X}$. (2011). Commodification and the selling of ethnic music to tourists. Geoforum , 42(4) (4), 496-505.

Sudibyo, A., \& Patria, N. (2013). The television industry in post-authoritarian. Journal of Contemporary Asia , 43 (2), 257-275.

Sundari, Z. A. (2018, Januari 13). Indosiar siapkan Rp 1 Miliar untuk pemenang LIDA. Dipetik Januari 22, 2020, dari Liputan6.com: https://www.liputan6. com/showbiz/read/3224456/indosiarsiapkan-rp-1-miliar-untuk-pemenanglida

SWA Online. (2003, Desember 10). Seni Menggelindingkan TV Baru. Dipetik
Januari 24, 2020, dari SWA Online: https://swa.co.id/swa/listed-articles/ seni-menggelindingkan-tv-baru

Terranova, T. (2000). Free labor: Producing culture for the digital economy. Social text, 18 (2), 33-58.

Toffler, A. (1980). The third wave. New York: Bantam.

Totona, S. (2010). Representasi kemiskinan sebagai praktik komodifikasi: Kajian atas program reality show kemiskinan di televisi. (Master Thesis, Universitas Gadjah Mada). Diambil dari http:// etd.repository.ugm.ac.id/home/detail_ pencarian/46354.

Tribunjambi.com. (2019, Mei 4). Detikdetik Menegangkan Faul dari Aceh Diumumkan Juara LIDA 2019, Uang Tunai \& Kontrak yang Didapat! Dipetik Januari 24, 2020, dari Tribunjambi.com: https://jambi. tribunnews.com/2019/05/04/detikdetik-menegangkan-faul-dari-acehdiumumkan-juara-lida-2019-uangtunai-kontrak-yang-didapat

Weintraub, A. N. (2006). Dangdut soul: who are 'the people' in Indonesian popular music? Asian Journal of Communication , 16 (4), 411-431.

Weintraub, A. N. (2010). Dangdut stories: A social and musical history of Indonesia's most popular music. New York: Oxford University Press.

Widodo, A. (2010). Bedah Rumah: Komodifikasi kemiskinan dan budaya konsumsi. Capture: Jurnal Seni Media Rekam , 1 (2), 112-119.

Widowati, H. (2019, Januari 11). Dipetik Mei 8, 2020, dari Katadata.co.id: https:// katadata.co.id/berita/2019/01/11/ tumbuh-13-belanja-iklan-televisitembus-rp-110-triliun-tahun-2018 